\title{
MAUERSCHAU: A Mobile Virtual Museum - Postmodern Storytelling through Digital Media
}

\author{
Maximilian von Grafenstein \\ Mauerschau Medienproduktion UG \\ Weinmeisterstr. 9b, 10178 Berlin \\ Germany \\ grafenstein@mauerschau.com
}

\author{
Eva Schneider \\ Technische Universität Berlin \\ Straße des 17. Juni 135, 10623 Berlin \\ Germany \\ schneider@tu-berlin.de
}

\author{
Nancy Richter \\ Institute for Internet and Society \\ Oberwallstr. 9, 10117 Berlin \\ Germany \\ nancy.richter@hiig.de
}

\section{INTRODUCTION}

MAUERSCHAU is a project of Mauerschau Medienproduktion UG, a Berlin based start-up consisting of filmmakers, programmers, humanists, and economists. Our team develops innovative product and business models between the New Media and classic high quality content. Referring to the method of Old Greek theatre "teichoscopy", our start-up provides, based on techniques of the New Media, access to cultural, historical, and fictional content which classic media productions could not appropriately grant.

\section{POSTMODERN THROUGH NON-LINEAR AND INTERACTIVE STORYTELLING}

With our MAUERSCHAU app, we pursue several aims on different dimensions: Conceptually, referring to teichoscopy, we follow the approach of postmodern storytelling by using new techniques of non-linear and interactive audiovisual storytelling. In doing so, we target younger generations. This is based on the assumption that their user behaviour has, in light of New Media enabled them to participate at a much higher level than classic media. As a consequence, and stemming from this belief, we attempt to apply new business models for financing the development and production of media content in the Internet. Classic media productions contemporarily suffer under the present situation that the Internet, on the one side, narrows down their classic revenue streams and, on the other side, enforces them to invest into research and development in order to adapt to the changed behaviour of consumers.

\subsection{Teichoscopy as an Approach of Postmod- ern Storytelling}

Regarding the concept, teichoscopy, also known as "viewing from the wall" (in German: Mauerschau), is a storytelling technique that provides insights into one or many events that are being observed from a wall, balcony, or window. The storyteller is a witness who describes an event as it unfolds in front of his eyes to others. This way of storytelling is opposite to an action described by a messenger after an event, and who will provide a linear and detailed understanding of certain actions. Usually, the advantage of teichoscopy, compared to a messenger's narrative, is seen as a higher dramatic perception because of the simultaneity of what is happening and what is being told. MAUERSCHAU builds upon this distinction, seeking to increase the user's immersion into what is being told through the use of non-linear and interactive storytelling techniques in order to blur the line between past events and present history.

Therefore, we transpose a postmodern theory for the presentation of history into non-linear and interactive stories. Understanding the underlying principles and concepts of storytelling provided for by Digital Media helps us to strategically use the possibilities for historical reflection and understanding. There is an essential difference between modern and postmodern discourses. Whereas modern narrations build an "era by era theory", postmodern narration styles are based on an "active-reactive struggle". With MAUERSCHAU, we add a postmodern non-linear and interactive storytelling fashion to classical narrations. Our app provides conflicting perspectives and stories about the erection and fall of the Berlin Wall, which allows a plurality of meanings and interpretations. Postmodern storytelling avoids a prevailing aspect of modern storytelling - whose concept could be interpreted as an "act of domination".

\subsection{Non-linear and Interactive Storytelling Techniques}

Following this approach, we implemented the concept on a practical level by using techniques of interactive storytelling: First of all, we follow different 
threads of a story happening at one moment. We aim to give the impression of different stories taking place at one location, just like the storyteller, who is standing on a wall or balcony - a position that enables him to see many events taking place the same time. As an example, the story of the eyewitness Karl-Heinz Schäfer, who was the commander in chief of the GDR troops responsible for the unhindered boarder control at Checkpoint Charlie. The tank-off of the 1963 crisis is shown within archive videos originating from both Western and Eastern German broadcasting companies. The eyewitness Karl-Heinz Schäfer then leads the user of the Mauerschau-App through these different perspectives explaining his personal point of view.
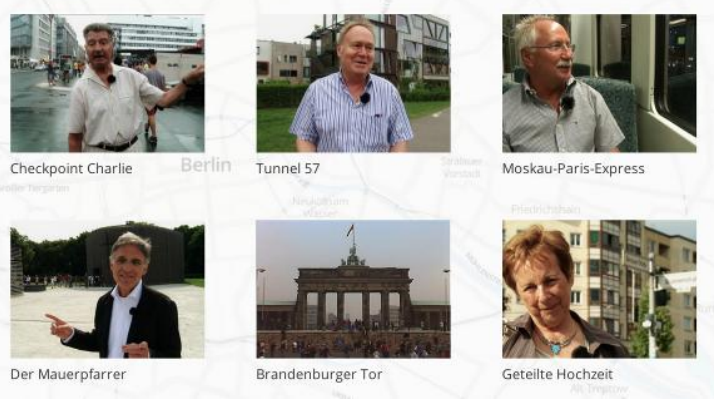

Figure 2: Personal stories of eyewitnesses

Another important aspect is that the eyewitnesses personally guide the user right to the places where their stories really happened. This location-based technique serves in combination with augmented reality technology for photographs and $360^{\circ}$ cinematic staging for video documentaries another element in order to make the user feel that the story he is being told takes place at the certain moment he is following it. Through the mapping of the original photo and video material to the places where it was taken, the user is able to directly merge the place from today and before.

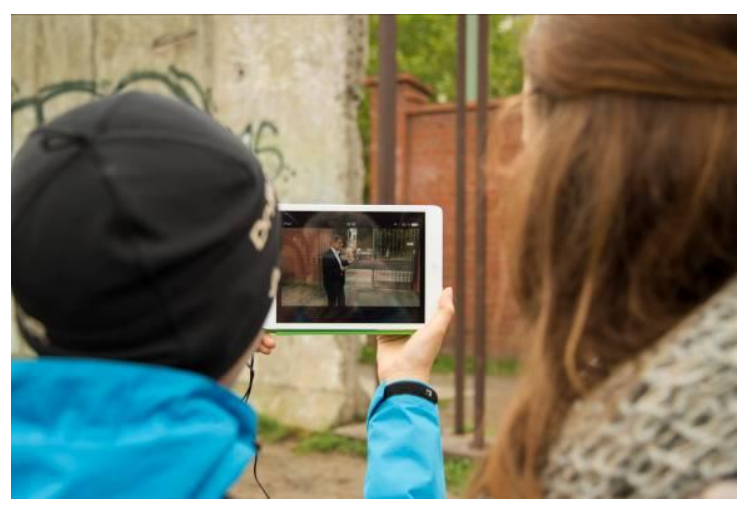

Figure 3: Manfred Fischer at the Berlin Wall

\section{CONCLUSION}

In retrospect, we came to the result that while digital media usually provide solutions for problems of commodity, they can also provide the infrastructure for new techniques of storytelling. However, using Digital Media goes in line with principally never ending production costs. The rapid development of Internet technology and user expectation enforces the producers to constantly adapt the product to the current state of the art and mind. This raises the question on how to finance these development and production costs. It is a question of highest interest, in particular, for all classic media, since their traditional business models are under pressure, given the changed user behaviour in the Digital Age.

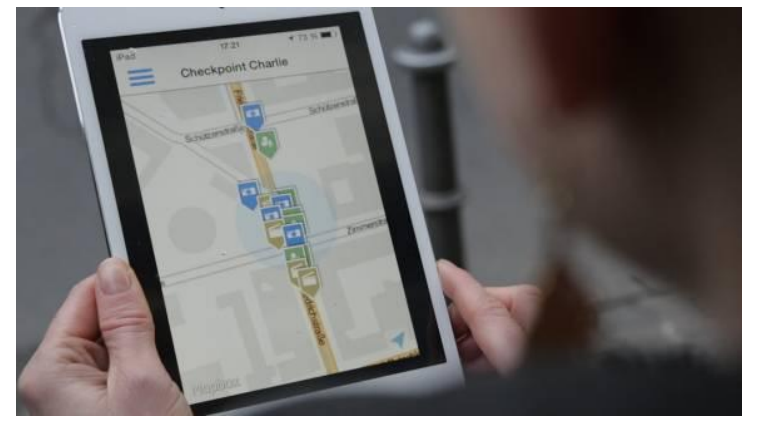

Figure 2: Street map with different marker

In our case, the public honoured our concept with more than 3,600 downloads in few months. However, our business model failed, which is based on a free version including two tours and further paid tours offered via an In-App Purchase model. One reason for this failure is certainly the "for free culture" in the Internet. This phenomenon comes along with an emerging conflict between private and public providers of cultural goods. While the first usually monetizes their products on the enduser market, the second offers their services, given their public mandate, for free. The more media converge, the more these public and private entities get into conflict offering their services and products on the same media market. However, the lack of willingness of our users to pay for the tours leads us to the conclusion that a mobile virtual museum such as ours cannot actually be funded privately. One solution to this problem could be to get it financed by a consortium of several public museums and to offer the product, as a consequence, for free. Supposed that users as well as museums would see value in the overall approach described of postmodern storytelling, this solution would have two essential advantages: Firstly, it would serve a common technical infrastructure for all mobile museum services reducing the overall production costs. Secondly, it would simultaneously enable users to keep an overview on mobile museum services instead of being overwhelmed by a dozen of apps scattered, often undiscovered, on the market.

Here we have summarised our conceptual approach, the techniques used in order to practically implement it, and the underlying business model. 